\title{
Adverse Event without Identified Device or Use Problem
}

National Cancer Institute

\section{Source}

National Cancer Institute. Adverse Event without Identified Device or Use Problem. NCI Thesaurus. Code C76126.

An adverse event appears to have occurred, but there does not appear to have been a problem with a medical device or the way it was used. 